\title{
Regeneration of Electrical Energy from Waste Geothermal Fluid in Geothermal Power Plants
}

\author{
${ }^{1}$ Mahmut Hekim and ${ }^{* 2}$ Engin Cetin \\ ${ }^{1}$ Vocational College of Technical Sciences, Karamanoglu Mehmet Bey University, Turkey \\ ${ }^{2}$ Department of Electrical\&Electronics Engineering, Faculty of Engineering, Pamukkale University, Turkey
}

\begin{abstract}
Geothermal power plants are the plants that provide the conversion of thermal energy in geothermal fluid to electrical energy as a result of the extraction of underground hot water resources to the earth by drilling. The total installed power of geothermal power plants in the field of geothermal resources in Turkey has reached 1,336 MW. The geothermal fluid, which is used for electric power generation in geothermal power plants, is re-injected into the underground wells after electrical energy production. For efficient generation of electrical energy in geothermal power plants, it is aimed to reuse the waste heat energy within the geothermal fluid before it is sent to the re-injection well. To achieve this aim, thermoelectric generator modules which convert waste heat energy to electrical energy can be used. In this study, a thermoelectric generator-based geothermal power plant simulator that converts geothermal fluid waste heat into electrical energy is installed and commissioned in the laboratory conditions.
\end{abstract}

Keywords: Geothermal power plants, waste heat energy, thermoelectric generator.

\section{Introduction}

It is known that energy demand increases with the development level of countries and the way to meet this energy requirement is to produce electricity with fossil fuels or renewable energy sources. While meeting the increasing energy demand by obtaining electricity from fossil fuels, it should be noted that both the damages to nature and the fossil fuel reserves tend to be depleted [1]. Therefore, the share of electricity production using renewable energy sources in total electricity production should be increased. The establishment and operation of Geothermal Power Plants (GPP), which can generate electricity using different technologies and methods using underground heat energy, is also of great importance in this context.

According to the latest data, the installed capacity of GPP in Turkey has reached 1,336 MW [2]. The geothermal energy potential in Turkey is observed not at a level to compete with fossil energy sources. However, GPPs offer significant advantages due to their domesticity, renewability, environmental pollution, ability to produce electricity throughout the year, cheapness, easy installation and sustainability. In geothermal fields which are not used for energy production and have a geothermal fluid between $90{ }^{\circ} \mathrm{C}$ and $125^{\circ} \mathrm{C}$, it is necessary to engage in $\mathrm{R} \& \mathrm{D}$ activities in order to activate the idea of establishing GPP and to enable these plants to operate more efficiently by obtaining electrical energy from waste thermal energy in GPPs [3].

*Corresponding author: Address: Faculty of Engineering, Department of Electrical\&Electronics Engineering, Pamukkale University, 20040, Denizli TURKEY. E-mail address: engincetin @ pau.edu.tr, Phone: +902582963747 
In this study; in order to increase energy efficiency in GPPs, a system designed to reuse the geothermal fluid used in the power plant before returning to the re-injection well is mentioned. The main structure of the system consists of Thermoelectric Generator Modules (TGM) which can generate electrical energy from thermal effect. The system as a whole is called the Thermoelectric Generator (TEG) System. Energy production in TGMs is the result of the Seebeck Effect. With this effect, within the system, with the temperature difference between the two surfaces of the TGM (hot and cold), DC electrical energy can be generated. In the designed system, TGMs are connected in series and parallel to increase the output power of the system. The system was modeled and simulated with Matlab-Simulink software.

\section{Design of the Thermoelectric Generator System}

The TEG System was firstly modeled in Matlab-Simulink platform and then the installation phase was started.

In this study, Kryotherm TGM 199-1.4-0.8 model TGMs were used. TGMs are p-n junction semiconductor materials and their general structure is presented in Figure 1. The technical characteristics of the TGMs used in this study are presented in Table 1 and the TGM configuration is shown in Figure 2.

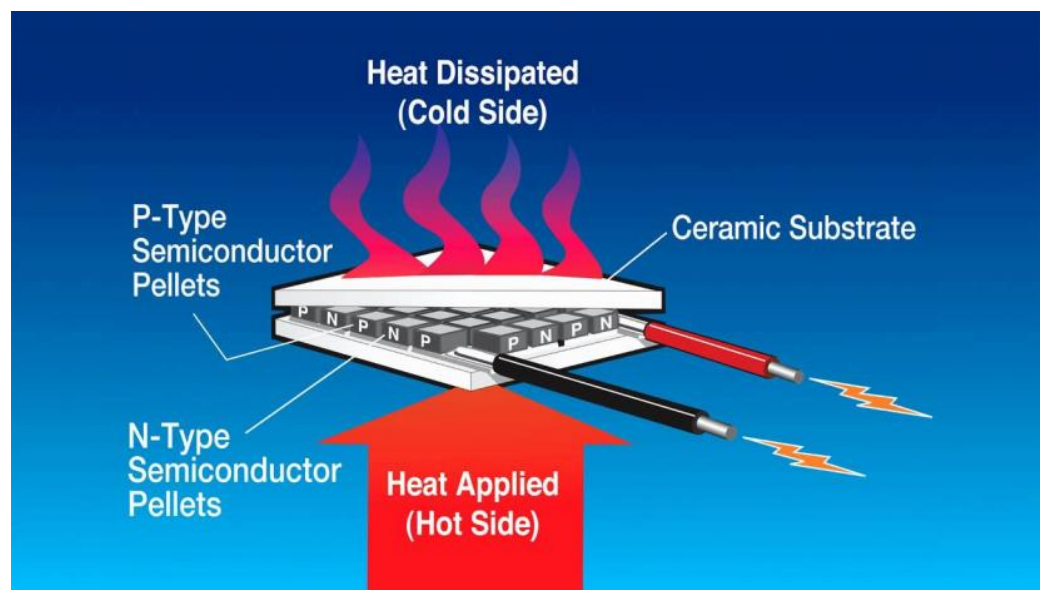

Figure 1. Termoelectric generator [4]

Table 1. Technical specifications of Kryotherm TGM 199-1.4-0.8 [5]

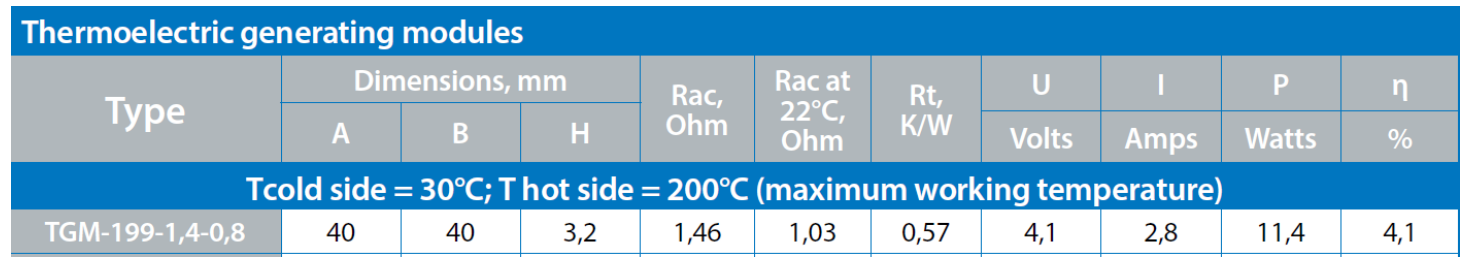




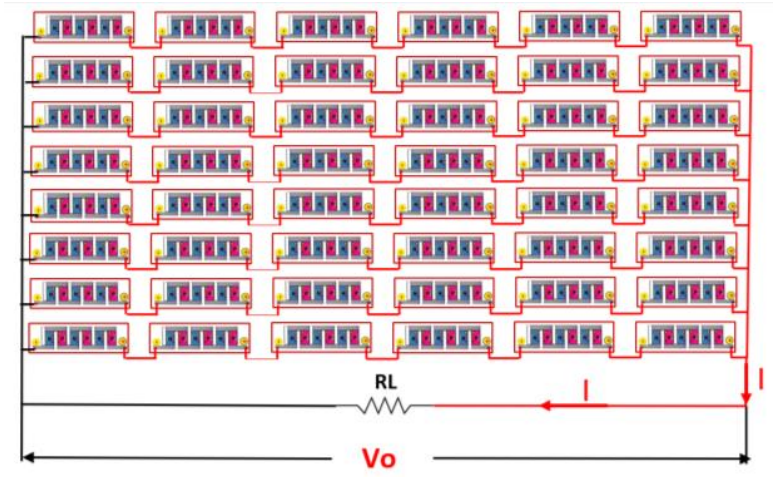

Figure 2. TGM configuration in series and parallel

For selected TGM, the values given in Table 1 are applicable for cold surface of $30{ }^{0} \mathrm{C}$ and hot surface of $200{ }^{\circ} \mathrm{C}$. However, geothermal fluid was considered as $100{ }^{0} \mathrm{C}$ and cooling water as 20 ${ }^{0} \mathrm{C}$. Therefore, according to the technical data received from the manufacturer for the new situation; TGM output voltage will be $2 \mathrm{~V}$ and output power will be $3.2 \mathrm{~W}$. Based on this data; six TGMs were connected in series to form a line. In total, eight lines are connected in parallel. Thus, fourtyeight TGMs will be used in the whole system as shown in Figure 2. Consequently, the DC output voltage of the system is $12 \mathrm{~V}$. This voltage value will be increased and applied to an inverter to obtain $230 \mathrm{~V} / 50 \mathrm{~Hz}$ AC output. The system was modeled in Matlab-Simulink platform. The block diagram of the simulated TEG System in Matlab-Simulink interface is presented in Figure 3. Seebeck Coefficient $(s)$, Quality Factor (Figure of Merit-Z), Thermal Conductivity Value $\left(K_{t h}\right)$, TGM Electrical Data and TGM number can be entered to Matlab-Simulink model by an operator. This allows the voltage $\left(V_{G E N}\right)$, current $\left(I_{G E N}\right)$ and power $\left(P_{O}\right)$ values of the TEG System to be obtained. Figure 4 shows examples of electrical data obtained from Matlab-Simulink simulation.

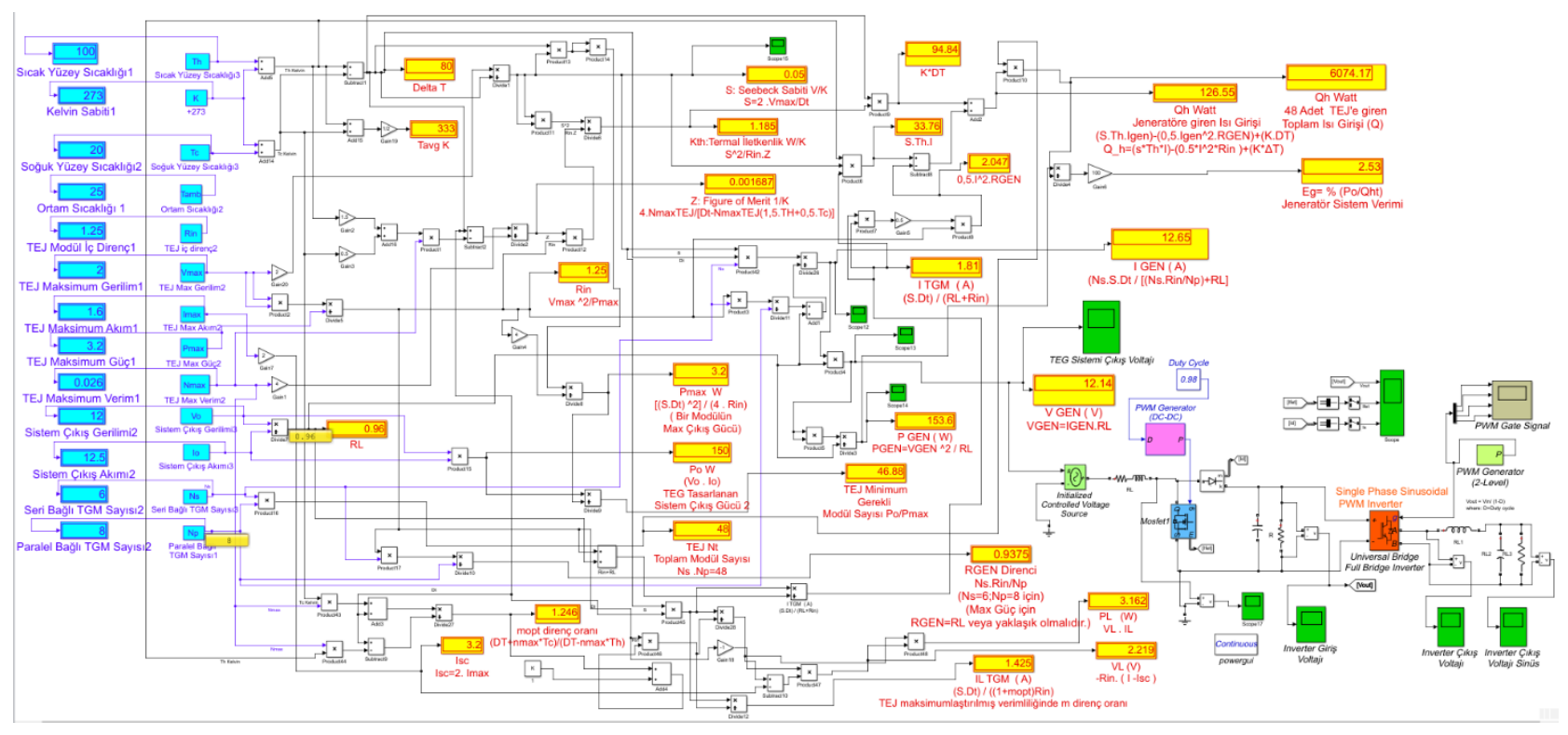

Figure 3. Matlab-Simulink model of TEG system [6] 

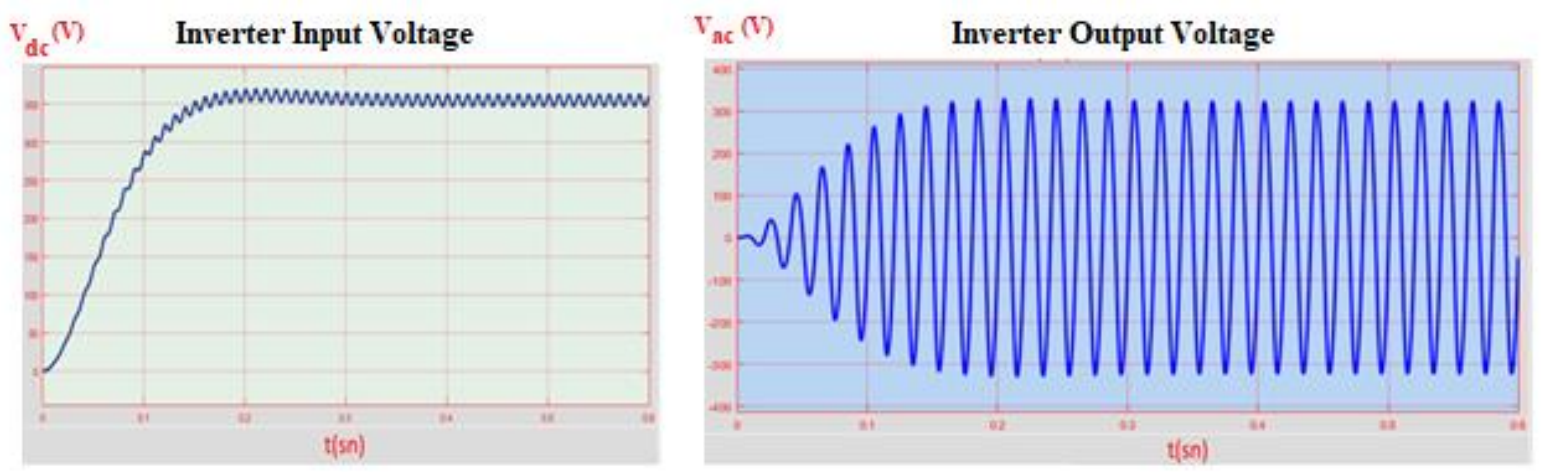

Figure 4. Increased DC input voltage and AC output voltage waveforms from Matlab-Simulink simulation

\section{Application of the Thermoelectric Generator System}

The TEG System, which has 48 TGMs, is shown in Figure 5. The two blue tanks shown in Figure 5 represent the geothermal well on the left and the cooling system on the right. The temperature of the water in the left tank is increased to $100{ }^{\circ} \mathrm{C}$ by means of three-phase resistive heater which is installed in the tank. The heated water passes through the hot section of the TGM block in the gray horizontal rectangular box in the middle of the system. Cold water which is in the cooling tank is circulated through the cold section of the TGM block. Temperature of the cooling tank can be decreased to $+4{ }^{\circ} \mathrm{C}$. In order to carry out these operations, two separate circulation pumps are used in the system. The general principle diagram of the system is presented in Figure 6.

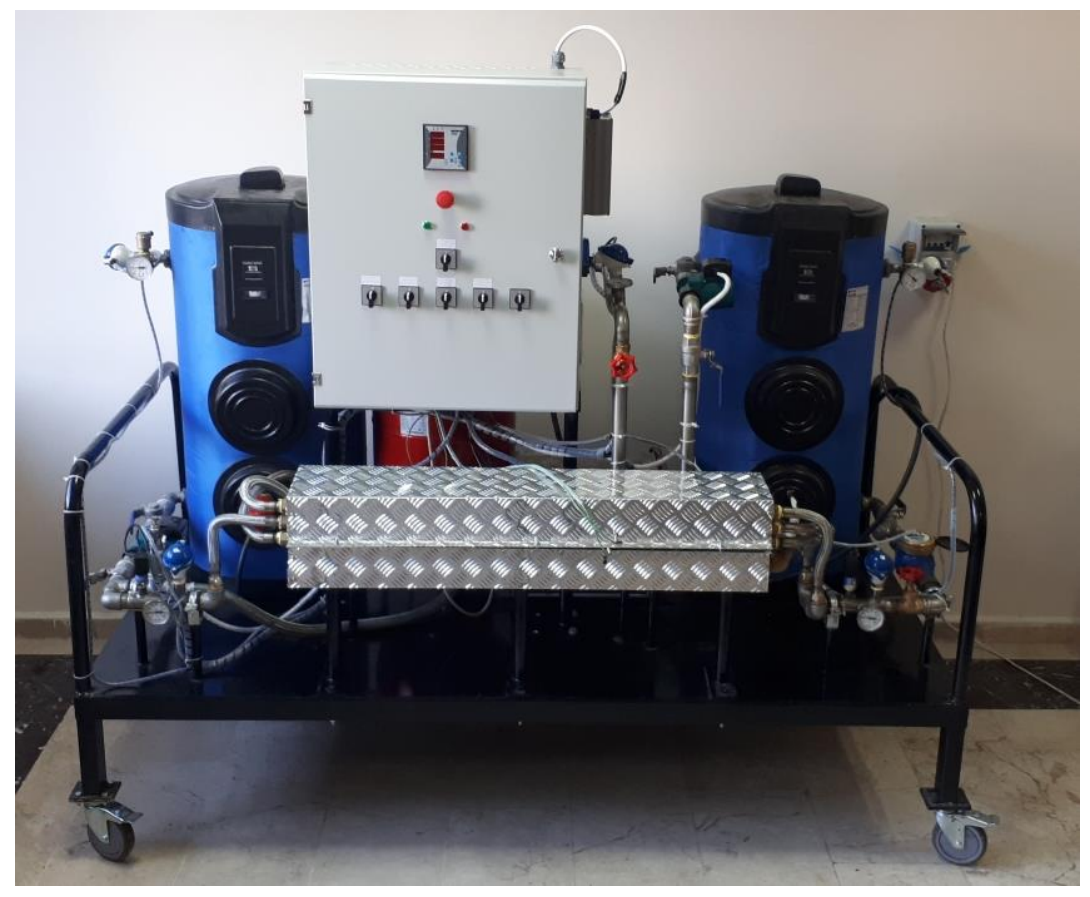

Figure 5. The TEG System 


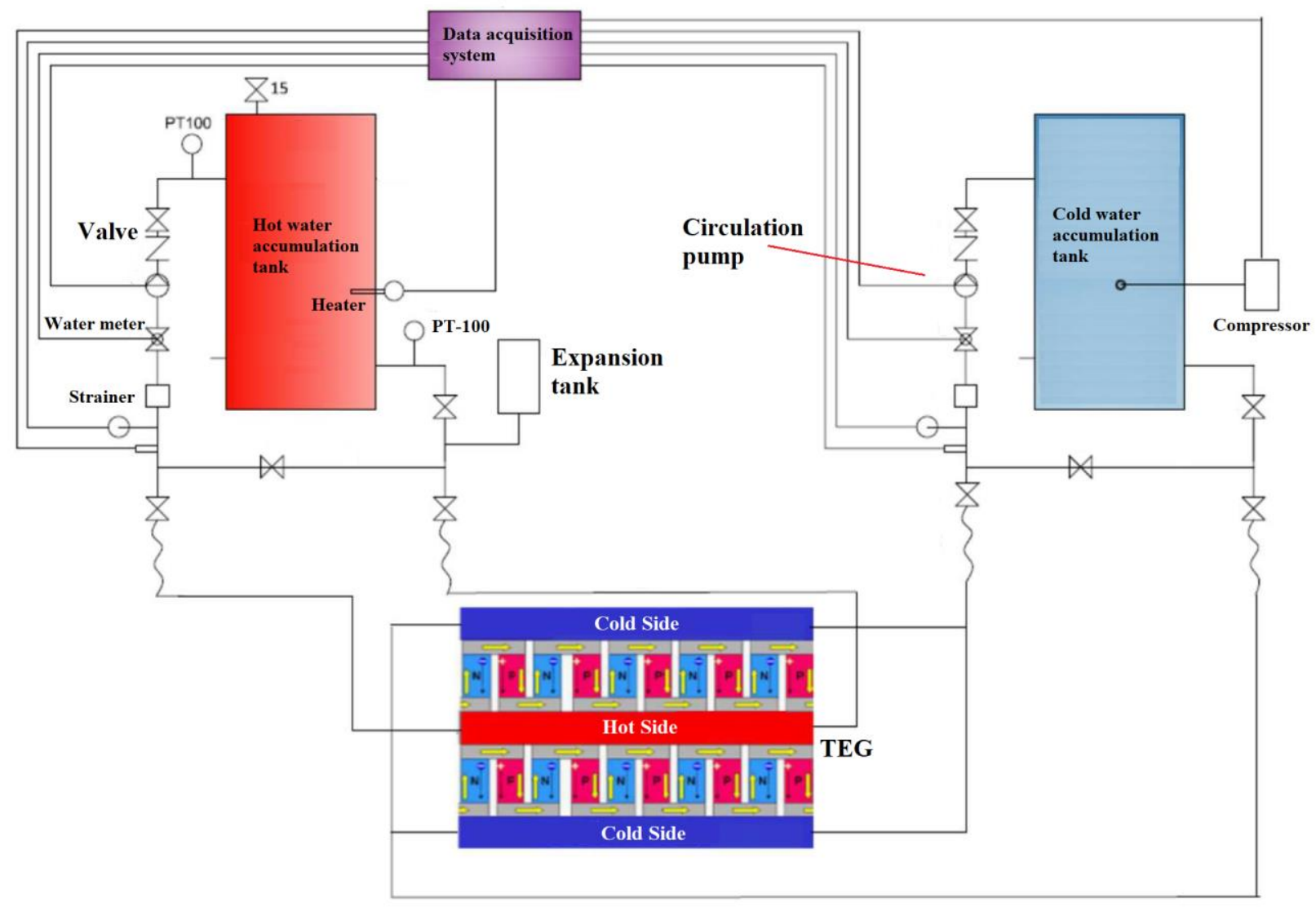

Figure 6. The TEG System with hot/cold water circulation equipment

Each of hot and cold water tanks used in the system has a capacity of $100 \mathrm{lt}$. In TGMs, the electrical power obtained from the TEG System can be increased by increasing the temperature difference $(\Delta t)$ between hot and cold surfaces [7]. For this purpose, the temperature of the hot water accumulation tank is increased by a resistive heater, and the water in the cold water accumulation tank is cooled by a compressor. Provided that all other connections of the system remain the same, to make the system operable in a real GPP, only the hot water accumulation tank can be replaced by a hot water line in an existing GPP, and the cold water accumulation tank is replaced by a cold water line in the GPP. When the system is operated in a GPP, there is no need to use additional pumps to ensure water flow.

All TGMs in the TEG System are mounted on two separate copper profiles, as shown in the connection diagram in Figure 6. PT100 temperature sensors are installed on these copper profiles. In the electrical panel of the TEG System shown in Figure 5 and Figure 7, there are a S7-1200 PLC unit, its analog modules and signal converters. With the PLC-based data acquisition system, some data such as voltage, temperature, pressure and hot/cold fluid flow rate can be monitored and recorded. Hot water and cold water pumps in the TEG System can be commissioned automatically with PLC-based data acquisition and control system. 


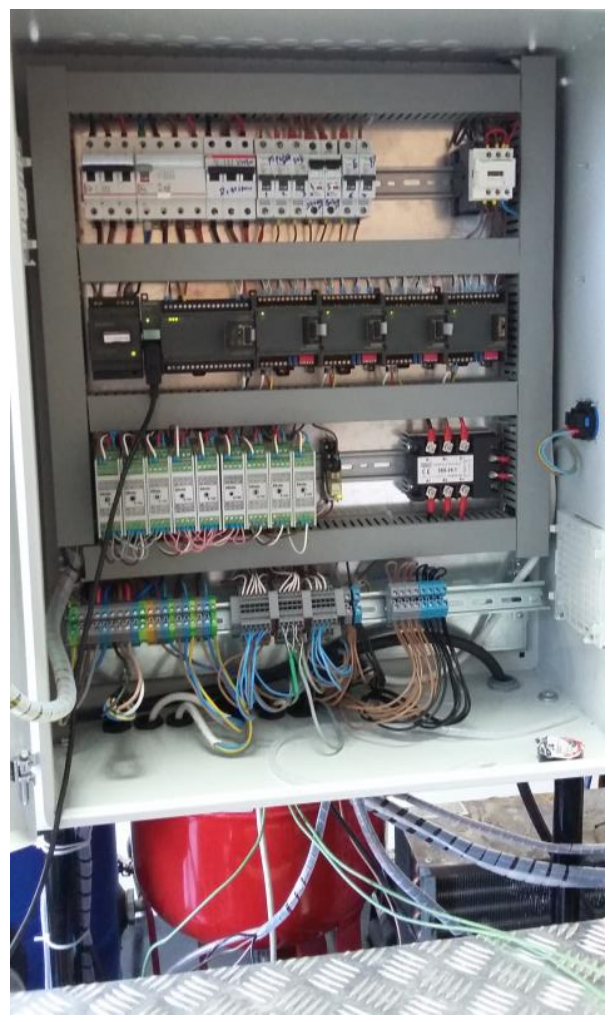

Figure 7. PLC-based control system

\section{Results and Discussion}

In this study, the TEG System which is designed and applied for generating electricity from waste geothermal fluid in GPPs by using TGM modules is mentioned. The designed system has been realized in a way that it can work both under laboratory conditions and under real power plant conditions. The designed TEG System is fully installed and operational. Installation and calibration process of analog modules and converters of PLC-based control system is being proceed. In the forthcoming period, it is aimed to complete the commissioning of the TEG System and applying the $12 \mathrm{~V}$ DC voltage obtained from the system to the $150 \mathrm{~W} / 230 \mathrm{~V}$ inverter unit to generate AC power.

The realized TEG System can be applied in the GPPs which are still in operation. Thus, in the existing GPPs, it will be possible to re-generate electricity from the geothermal fluid going to the re-injection well as a result of a secondary process. In this way, the amount of electrical energy obtained from the power plant will increase. It is believed that there will be a trend for the implementation of the established TEG System to the existing GPPs. During the operation of a GPP, there are no major technical and economic costs in order to obtain the temperature difference required for the operation of the TEG System. Because, while the GPP is in operation, the hot water required for the operation of the TEG System will be supplied from the return water line of the power plant and cold water from the cooling water line of the power plant. The TEG System will 
be operational in parallel with the existing system while the GPP is in operation. In addition, there will be no additional requirements for the TEG System such as water heating, water cooling, inhibitor dosing to prevent calcification of the geothermal well, and consuming additional electrical energy to ensure water circulation.

\section{Acknowledgments}

The authors would like to thank the Commission of Scientific Research Projects of Pamukkale University for its support with this study (Project no: 2017FEBE027).

\section{References}

[1] Cetin E., Hekim M., Yilanci A., Ozturk H. K., Colak M., Kasikci I. PLC-Based Measurement of Electrical Datas in Photovoltaic Energy Systems. International Conference on Applied Electronics: 2009, September 9-10, Pilsen-Czech Republic.

[2] http://direnc.blog/wp-content/uploads/2019/09/Ekim2019_Elektrik$\% \mathrm{C} 4 \%$ B0statistikleri.pdf

[3] Özden H., Paul D. Organik Rankin Çevrim Teknolojisiyle Düşük Sıcaklıktaki Kaynaktan Faydalanılarak Elektrik Üretimi. Örnek Çalışma: Sarayköy Jeotermal Santrali. X. Ulusal Tesisat Mühendisliği Kongresi: 2011, 13-16 Nisan, İzmir, 101-108.

[4] https://www.youtube.com/watch?v=YhynSkFlJOs

[5] http://kryothermtec.com/assets/dir2attz/Kryotherm\%20catalog.pdf

[6] Hekim M., Cetin E. Jeotermal Enerji Santrallerine Yönelik Termoelektrik Jeneratör Sistem Modellemesi. CIGRE Güç Sistemleri Konferansı: 2018, 15 - 16 Kasım, The Ankara Hotel, Ankara, 99-104.

[7] Ahıska R., Mamur H., Ulis M. Termoelektrik Modülün Jeneratör Olarak Modellenmesi ve Deneysel Çalışması. Gazi Üniversitesi Mühendislik-Mimarlık Fakültesi Dergisi, 2011; 26(4): 889-896. 